\title{
Effect of Malted and Unmalted Finger Millet Flour and Its Rates of Incorporation on Quality Attributes of Finger Millet Enriched Probiotic Fermented Milk Product
}

\author{
Aijaz M. Shaikh", V. Sreeja and Rachana R. Desai \\ Dairy Microbiology Department, S.M.C. College of Dairy Science, Anand Agricultural \\ University, Anand-388110 Gujarat, India \\ *Corresponding author
}

\begin{abstract}
A B S T R A C T
In the current study, two forms of finger millet flour viz., malted and unmalted were used to prepare finger millet enriched probiotic fermented milk products. Both forms were

Keywords

Finger millet, malting, Probiotic, Fermented milk, Quality attributes.

Article Info

Accepted:

23 July 2017

Available Online:

10 September 2017 incorporated in toned milk at 10\%, 15\%, 20\% rates and fermented using probiotic Lactobacillus helveticus MTCC 5463 and Streptococcus thermophiles MTCC 5460. Fermented product without finger millet served as control. Products were analysed for titratable acidity, sensory and microbiological parameters. The study results revealed that use of malted and unmalted finger millet had a significant $(\mathrm{p}<0.05)$ effect on the probiotic and streptococcal counts and the counts were found to be higher in products made using malted flour. But the acidity and sensory attributes were not much affected by forms of finger millet. Even though not significant, the overall acceptability score of products containing malted flour was found to be higher than products with unmalted flour. Rates of incorporation of finger millet had a significant $(\mathrm{p}<0.05)$ effect on all quality aspects. Compared to control, finger millet incorporated products showed higher titratable acidity and culture counts. Acidity as well as counts increased with increased rate of finger millet incorporation. Even though the sensory attributes of control was found superior to finger millet added products all the enriched products were acceptable and the liking was found to be more towards malted products.
\end{abstract}

\section{Introduction}

Milk and its fermented products are being well recognized for their nutritional and functional aspects hence are made an integral part of the daily diet of people of all age groups throughout the world. Dairy products are excellent media to generate an array of products that fit to current consumer demand for functional foods. Fermented dairy products enriched with probiotic bacteria have developed into one of the most successful category of functional foods and the market of such probiotic dairy foods is increasing annually (Lye et al., 2009). Even though milk is considered as an almost complete food, it is deficient in dietary fibre, micronutrients such as iron and vitamin $\mathrm{C}$.

Finger millet or Ragi (Eleusinecoracana) is one of the common millets in several regions of India and is a good source of dietary fibre (Desai et al., 2010). This millet is exceptionally rich in calcium $(344 \mathrm{mg} / 100 \mathrm{~g})$ 
compared to all other cereals and millets and contains $283 \mathrm{mg} \%$ phosphorus, $3.9 \mathrm{mg} \%$ iron (Gopalan et al., 2009), and many other trace elements and vitamins. Potassium content of finger millet is also high $(408 \mathrm{mg}$ $\%)$ compared to other cereals and millet. The nutritive value of finger millet is better than other cereals (Manay and Shadaksharaswamy, 2001). It contains important amino acids such as isoleucine $(4.4 \mathrm{~g})$, leucine $(9.5 \mathrm{~g})$, methionine $(3.1 \mathrm{~g})$ and phenyl alanine $(5.2 \mathrm{~g})$ which are deficient in other starchy meals. Millets also contains B vitamins, especially niacin, B6 and folic acid. Additionally it is being studied for its health benefitting properties such as antimicrobial (Chethan and Malleshi, 2007; Isingoma et al., 2015), antioxidant (Chethan and Malleshi, 2007; Chandrasekara and Shahidi, 2010), cholesterol lowering (Mathanghi and Sudha, 2012; Dayakarrao et al., 2016), blood glucose lowering effect (Rachie and Peters, 2002; Rajasekaran et al., 2004; Glewet al., 2008; Mathanghi and Sudha, 2012), nephro protective (Dayakarrao et al., 2016; Mathanghi and Sudha, 2012), anticataractogenic (Mathanghi and Sudha, 2012), anti-inflammatory (Taylor et al., 2006; Taylor and Emmambux, 2008; Chandrasekara and Shahidi, 2011b and 2011c), antiviral (Mathanghi and Sudha, 2012), anticancer (Thompson, 1993), and antidiabetic effect (Mathanghi and Sudha, 2012). Finger millet as potential prebiotics contains good amount of healthy components (Manisseri and Gudipati, 2012). As the millets are gluten free, it has considerable potential in foods and beverages which can meet the growing demand for gluten free foods.

Cereals and milk are blended to compensate for deficiency of each other in a number of research studies (Aneja et al., 2002, Mugocha et al., 2000, Modha and Pal, 2011, Addis et al., 2013, Chaudhary, 2013, Pardhi et al., 2014, Shivakumar et al., 2014, Isingoma et al., 2015, Chilakawar et al., 2015, Patel et al.,2015). While combining milk and cereal for obtaining nutritional benefits, it is essential that we need to understand the effect of level of cereal incorporation as well as the effect of its forms in the physico-chemical, sensory as well as microbiological aspects of the resultened product. In case of a fermented product, it is also essential to study the effect of cereal incorporation on starter or probiotic culture growth and activity. Additionally very few research reports are available related to combining the nutritional aspects of milk, finger millet and fermentation. Hence, the present study was planned and executed.

\section{Materials and Methods}

Toned milk (3.0\% milk fat, $8.5 \%$ MSNF) for the preparation of finger millet enriched probiotic fermented milk product was obtained from Vidyashoppe Anand, Gujarat, India. Finger millet variety PRM 9802 (dark colored) of AGMARK (Grade I) was procured from local supermarket of Anand, Gujarat, India. Indigenous starter culture used in the preparation of product comprised of Streptococcus thermophilus MTCC 5460 and probiotic strain Lactobacillus helveticus MTCC 5463.

Both cultures were obtained from the culture collection of SMC College of Dairy Science, Anand Agricultural University, Anand, Gujarat, India. Lactobacillus helveticus has been proven for its potential as probiotic. All the cultures were propagated in sterilized reconstituted skim milk (10\% T.S.) medium by incubation at $37 \pm 1^{\circ} \mathrm{C}$ for $8-12 \mathrm{~h}$ and stored at $5 \pm 2^{\circ} \mathrm{C}$. Three successive transfers of cultures were givenin the same medium prior to their use to ensure activity of cultures during the course of the study.

\section{Preparation of malted finger millet flour}

Malting of finger millet was carried out according to the procedure suggested by 
Chilakawar et al., (2015) with necessary modifications. Finger millet grains were weighed, dust, dirt were removed and washed well. The grains were kept for steeping in water for 12 hours at room temperature. The grains: water ratio was kept at 1:3. During steeping, the water was changed after every 4 hours.

It was then hanged overnight at room temperature to remove excess water. Steeped grains were spread on perforated trays lined with muslin cloth and germinated at $25 \pm 2{ }^{\circ} \mathrm{C}$ for $24 \mathrm{~h}$ in an incubator. The seeds were then spread uniformly on a stainless steel tray and dried in a vacuum tray dryer maintained at $40-45^{\circ} \mathrm{C}$ for 5 to $6 \mathrm{~h}$.

The malted, dried finger millet seeds were ground and made into flour using commercial flour mill (Milcent flour mill, compressioncum-shearing type (roller) mills, Ahmadabad) adjusted to a fine setting. Subsequently, the flours were sieved and stored in air-tight containers at $7 \pm 2^{\circ} \mathrm{C}$. The malted finger millet flour was given a heat treatment of $70^{\circ} \mathrm{C}$ prior to its incorporation in the milk during product preparation.

\section{Preparation of finger millet enriched probiotic fermented milk product}

Toned milk (3.0\% Fat, $8.5 \%$ SNF) was pre heated to $40^{\circ} \mathrm{C}$ and added with malted and unmalted finger millet flour at three different concentrations viz., $10 \%, 15 \%$ and $20 \%$ on milk basis. It was the mixed to ensure uniform mass. The mixture was then heated to $80^{\circ} \mathrm{C}$ for no hold. It was cooled to $40^{\circ} \mathrm{C}$ and inoculated with probiotic and strepotococcal culture@2\%. It was incubated at $\left(37 \pm 2{ }^{\circ} \mathrm{C}\right)$ till titratable acidity reached to about $0.7 \%$ LA. The product was then cooled $\left(5 \pm 2{ }^{\circ} \mathrm{C}\right)$ and the curd was broken to obtain a uniform viscous product. It was filled in HDPE bottles and stored at refrigeration temperature $\left(7 \pm 2^{\circ} \mathrm{C}\right)$.

\section{Titratable acidity}

The titratable acidity of the product was determined by the method described in the Indian Standards (IS: 1479-Part I, 1960).

\section{Sensory evaluation}

Sensory evaluation of the products for flavour, body, acidity, colour and appearance and overall acceptability was carried out by expert panel of judges using 9 point hedonic scale.

\section{Microbiological analysis}

Probiotic and streptococcal count were analysed according to methods described in Indian Standards (IS: 1479, Part III, 1962).

\section{Statistical analysis}

All the parameters under study were analyzed by statistical methods. Study data were analyzed by Completely Randomized Design and Factorial Completely Randomized Design as per the methods described by Steel and Torrie (1980). The values for microbial counts were log transformed before analysis.

\section{Results and Discussion}

Quality attributes of finger millet enriched probiotic fermented milk products as affected by forms and rates of incorporation of finger millet flour

During preliminary studies it was found that addition of finger millet flour resulted in an excessive viscosity in the product and impaired the quality attributes of the fermented product.

This necessitated a study to understand the effects of malted and unmalted finger millet flours and its rates of incorporation can have on quality attributes of the resulting finger 
millet enriched probiotic fermented milk product. The results of the study are given and discussed here under.

\section{Titratable acidity}

The effect of malted and unmalted finger millet and its rate of additions on titratable acidity of the products is shown in figure 1. It was observed that malted and unmalted finger millet had no significant ( $p>0.05)$ effect on titratable acidity of the product. The mean acidity value of products prepared using malted and unmalted finger millet, were 0.73 and $0.72 \%$ LA respectively. On the other hand, rates incorporation of finger millet had a significant $(\mathrm{P}<0.05)$ effect on acidity of the products. Compared to control $(\mathrm{C} 1)$, finger millet incorporated products showed a higher titratable acidity and it increased with increase in the rate of finger millet concentrations. Highest acidity (mean value $0.75 \%$ LA) was seen in product prepared using $20 \%$ finger millet flour.

Similar observation was reported by Pardhi et $a l$. , (2014) who added finger millet flour at different concentrations of $2 \%, 3 \%$ and $4 \%$ during the preparation of finger millet lassi. They reported an increase in the acidity of finger millet lassi with an increased level of finger millet flour. As not much scientific published data was available to see the effect of forms and rates of finger millet flour addition on titratable acidity of composite fermented milk products, a comparative discussion could not be done.

\section{Probiotic and Streptococcal counts}

Effect of different forms and levels of finger millet concentration on viability of Streptococcus thermophilus MTCC 5460 and probiotic Lactobacillus helveticus MTCC 5463 is shown in table 1. Forms as well as rates of addition of finger millet had a significant $(\mathrm{P}<0.05)$ effect on viability of both strains. The increase in counts were linear as the finger millet concentrations were increased from 0 to $20 \%$. The highest count was seen in fermented milk $\mathrm{C} 4$ containing $20 \%$ finger millet. Average count of both the strains in the products varied between 9 log $\mathrm{cfu} / \mathrm{g}$ to $>10 \log \mathrm{cfu} / \mathrm{g}$. Malted form supported the growth of both strains better than unmalted form. This may be because the malted millet is nutritionally superior to unmalted one as it is a good source of amylases and during germination, the amylases partially hydrolyze the starch to lower molecular weight carbohydrates such as oligo- and disaccharides (Shobana et al., 2013). When the malted flour is mixed with milk and heated, the amylases hydrolyze the starch to simple sugars (Malleshi, 2002a) which the lactic acid bacterial strains can utilize for their growth. There was no scientific published data on similar kind of work available to compare the effect of finger millet flour addition on streptococcal and probiotic counts of fermented milk products.

\section{Sensory attributes}

The sensory attributes of the products are shown in table 2 . Rate of additions of finger millet had a significant $(\mathrm{p}<0.05)$ effect on all the sensory attributes of the products. Highest mean score for flavour (7.85) was obtained for plain fermented milk (C1) which differed significantly $(\mathrm{p}<0.05)$ from finger millet added fermented milks C2, C3 and C4, which were at par with each other and all the products scored higher than 7 on hedonic scale indicating that the flavour of finger millet added products were accepted and liked by the expert panel of judges. However, forms of finger millet, malted as well as unmalted, did not affect the flavour of fermented milk products. The flavour scores were highest for products prepared using malted finger millet compared to the products made using 
unmalted finger millet. Pintu (2006) found that with an increase in the level of sorghum flour, a significant $(\mathrm{P}<0.01)$ decrease in flavour score was observed at linear levels (3, $3.73,5.5$ and 7.27) in rabadi-like beverage from sorghum and milk solids.

Table.1 Streptococcal and probiotic count of products as affected by forms and Rates of addition of finger millet

\begin{tabular}{lcccc}
\hline \multirow{2}{*}{$\begin{array}{c}\text { Forms of finger } \\
\text { millet }\end{array}$} & \multicolumn{4}{c}{ Rate of incorporation of finger millet } \\
\cline { 2 - 5 } & $\mathrm{C} 1(0 \%)$ & $\mathrm{C} 2(10 \%)$ & $\mathrm{C} 3(15 \%)$ & $\mathrm{C} 4(20 \%)$ \\
\hline \multicolumn{5}{c}{ Streptococcal count $(\mathbf{l o g}$ cfu/g) } \\
Malted & $9.67 \pm 0.0 .1$ & $10.36 \pm 0.02$ & $10.47 \pm 0.01$ & $10.92 \pm 0.02$ \\
Unmalted & $9.67 \pm 0.0 .1$ & $10.38 \pm 0.01$ & $10.32 \pm 0.02$ & $10.44 \pm 0.01$ \\
$\mathrm{CD}(0.05) \mathrm{F}=0.012, \mathrm{R}=0.017 ; \mathrm{FxR}=0.024$ & & \\
\hline \multicolumn{5}{c}{ Probiotic count (log cfu/g) } \\
Malted & $9.47 \pm 0.01 \quad 10.60 \pm 0.02$ & $10.95 \pm 0.15$ & $10.97 \pm 0.01$ \\
Unmalted & $9.47 \pm 0.01$ & $10.51 \pm 0.01$ & $10.68 \pm 0.02$ & $10.90 \pm 0.01$ \\
$\mathrm{CD}(0.05) \mathrm{F}=0.048, \mathrm{R}=0.068 ; \mathrm{FxR}=0.097$ & & \\
\hline
\end{tabular}

Each observation is a mean \pm SD of three replicate experiments

$\mathrm{F}=$ Forms of finger millet, $\mathrm{R}=$ Rate of incorporation of finger millet

Table.2 Effect of forms and rates of addition of finger millet on Sensory attributes of fermented milk products

\begin{tabular}{lcccc}
\hline \multirow{2}{*}{ Forms of finger millet } & \multicolumn{5}{c}{ Rate of incorporation of finger millet } \\
\cline { 2 - 5 } & $\mathrm{C} 1(0 \%)$ & $\mathrm{C} 2(10 \%)$ & $\mathrm{C} 3(15 \%)$ & $\mathrm{C} 4(20 \%)$ \\
\hline \multirow{5}{*}{ Malted } & $7.85 \pm 0.40$ & $7.35 \pm 0.25$ & $7.43 \pm 0.39$ & $7.37 \pm 0.15$ \\
Unmalted & $7.85 \pm 0.40$ & $7.20 \pm 0.21$ & $7.37 \pm 0.50$ & $7.36 \pm 0.39$ \\
$\mathrm{CD}(0.05) \mathrm{F}=\mathrm{NS}, \mathrm{R}=0.402 ; \mathrm{FxR}=\mathrm{NS}$ & & & \\
\hline \multicolumn{5}{c}{ Body score (Out of 9) } \\
Malted & $7.93 \pm 0.33$ & $7.56 \pm 0.16$ & $7.79 \pm 0.20$ & $7.60 \pm 0.25$ \\
Unmalted & $7.93 \pm 0.33$ & $7.29 \pm 0.14$ & $7.41 \pm 0.47$ & $7.54 \pm 0.43$ \\
$\mathrm{CD}(0.05) \mathrm{F}=\mathrm{NS}, \mathrm{R}=0.318 ;$ FxR=NS & & & \\
\hline \multicolumn{5}{c}{ Acidity score (out of 9) } \\
Malted & $7.91 \pm 0.44$ & $7.54 \pm 0.20$ & $7.68 \pm 0.12$ & $7.37 \pm 0.21$ \\
Unmalted & $7.91 \pm 0.44$ & $7.35 \pm 0.32$ & $7.45 \pm 0.19$ & $7.37 \pm 0.32$ \\
$\mathrm{CD}(0.05) \mathrm{F}=\mathrm{NS}, \mathrm{R}=0.365 ;$ FxR=NS & & & \\
\hline
\end{tabular}

$\mathrm{CD}(0.05) \mathrm{F}=\mathrm{NS}, \mathrm{R}=0.365 ; \mathrm{FxR}=\mathrm{NS}$

\begin{tabular}{lcccc}
\multicolumn{5}{c}{ Colour and appearance score (out of 9) } \\
Malted & $8.18 \pm 0.33$ & $7.39 \pm 0.28$ & $7.58 \pm 0.40$ & $7.37 \pm 0.18$ \\
Unmalted & $8.18 \pm 0.33$ & $7.27 \pm 0.32$ & $7.43 \pm 0.50$ & $7.25 \pm 0.40$
\end{tabular}

$\mathrm{CD}(0.05) \mathrm{F}=\mathrm{NS}, \mathrm{R}=0.437$; FxR=NS

\section{Overall acceptability score (out of 9)}

$\begin{array}{lllll}\text { Malted } & 7.90 \pm 0.42 & 7.50 \pm 0.32 & 7.58 \pm 0.33 & 7.49 \pm 0.16 \\ \text { Unmalted } & 7.90 \pm 0.42 & 7.48 \pm 0.19 & 7.48 \pm 0.36 & 7.47 \pm 0.38\end{array}$

$\mathrm{CD}(0.05) \mathrm{F}=\mathrm{NS}, \mathrm{R}=0.340 ; \mathrm{FxR}=\mathrm{NS}$

Each observation is mean \pm SD of three replicate experiments

$\mathrm{F}=$ Forms of finger millet, $\mathrm{R}=$ Rate of incorporation of finger millet 
Fig.1 Titratable acidity of fermented milk products as affected by forms and Rates of addition of finger millet

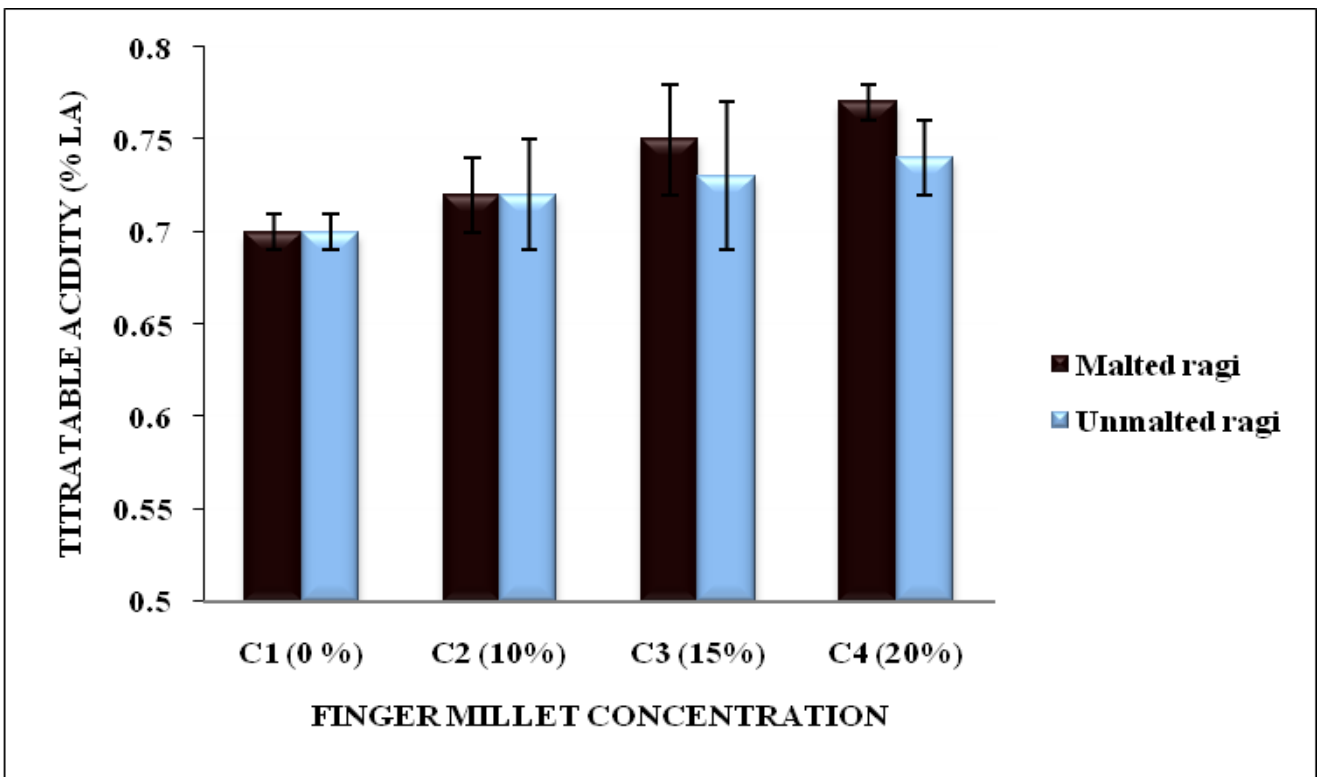

Forms of finger millet had no significant effect while the rate of additions had a significant $(p<0.05)$ effect on body of the products. Even through non-significant $(\mathrm{P}>0.05)$, the body score in fermented milks containing malted finger millet flour were found to be higher than the scores for products prepared using unmalted flour. But amongst all the products, control scored the maximum for body score (mean value 7.93). This may be because the control and finger millet enriched products differed in the body characteristics particularly in terms of smoothness of the body.

Even though the finger millet enriched products showed uniform body and flow characteristics, the presence of finger millet flour resulted in a coarse texture, which might have contributed to a coarse mouth feel in comparison to control which had a very smooth mouth feel. Mutoni (2011), reported that Pearl millet flour (PMF) decreased the consistency score in Pearl millet/milk based set yoghurt at linear level $(1.98,3,4.5,6$ and 7.02) and quadratic terms $(\mathrm{P}<0.05)$.
Martensson et al., (2002), reported that exopolysaccharides (EPS) producing LAB strains when used as starter increases the viscosity of oat based fermented product.

Even through non-significant $(\mathrm{P}>0.05)$, the acidity score as perceived by judges in fermented milks containing malted finger millet flour were found to be higher than the scores for products prepared using unmalted flour. The mean score for fermented milk containing, malted and unmalted finger millet flour ranged from 7.52 and 7.63 respectively. Among the different rates of incorporation of finger millet flour, control differed significantly $(\mathrm{P}<0.05)$ for acidity score compared to other products for them the scores were found to be at par. Among the finger millet containing products, incorporation of finger millet @ $15 \%$ scored the maximum for acidity score (mean value 7.57).Similar results reported by Pardhi et al., (2014), who prepared a finger millet based lassi containing 2, 3 and $4 \%$ finger millet flour and the acidity scores of products were found to be $7.24,7.33$ and 7.19 respectively. 
The colour and appearance score in fermented milks containing malted finger millet flour were found to be higher than the scores for products prepared using unmalted flour. The mean score for fermented milk containing, malted and unmalted finger millet flour ranged from 7.53 and 7.63 respectively. Among the different rates of incorporation of finger millet flour, control differed significantly $(p<0.05)$ for colour and appearance score compared to other products which were found to be at par. Among the finger millet containing products, incorporation of finger millet @ 15\% scored the maximum for colour and appearance score (mean value 7.51). Tarakci et al., (2004), prepared a fermented soup (tarhana) added with combinations of three flours viz., corn flour, wheat flour and corn flour + wheat flour with whey and yoghurt samples. They found that tarhana sample made with corn flour had a significantly higher colour score.

The effect of forms and rate of additions of finger millet on overall acceptability score of fermented milk products are shown in table 2 . Forms of finger millet had no significant ( $p>0.05$ ) effect while the rate of additions had a significant $(\mathrm{p}<0.05)$ effect on overall acceptability of the products. Even though non-significant $\quad(p>0.05), \quad$ the overall acceptability score in fermented milks containing malted finger millet flour were found to be higher than the scores for products prepared using unmalted flour. The mean score for fermented milk containing, malted and unmalted finger millet flour ranged from 7.58 and 7.62 respectively. The overall score was highest (7.90) for control (C1) which was found to be significant $(p<0.05)$ compared to experimental fermented milk samples, for them the scores were at par. Modha and Pal (2011) and Mutoni (2011) also reported that the overall preference of rabadi-like beverage and pearl millet/milk set yoghurt was dependent mostly and significantly $(\mathrm{P}<0.05)$ on flour. Anil and Anamika (2015) in their research study found that the overall acceptability of millet lassi increased as the level of sorghum flour was increased.

In conclusion, the current study has revealed that the use of malted finger millet flour improves the product quality attributes in comparison to unmalted flour especially in terms of probiotic and streptococcal counts and titratable acidity development. Rates of incorporation of finger millet had shown a significant $(\mathrm{p}<0.05)$ effect on all quality attributes. The counts, titratable acidity increased with increase in concentrations of finger millet. While sensorily, incorporation of finger millet and its rates affected the product attributes to some extent. But all the finger millet enriched products were acceptable and the liking was found to be more towards malted products.

\section{References}

Addis, G., Vasudeva S., Vishwas, P., Alok, S., Lalitha, G., Madhavan, A., and Bhattacharya, S 2013. Development and functional properties of low-cost complementary food. African Journal of Food Science, 7 (9), 274-284.

Aneja, R.P., Mathur, B.N., Chandan, R.C., and Banerjee, A.K. 2002. Technology of Indian milk products, (Dairy India Yearbook Publishers). New Delhi, India.

Anil, K., and Anamika, D. 2015. Quality evaluation of Sorghum based fermented milk beverage. The Pharma Innovation Journal, 4, 83-86.

Chandrasekara, A., and Shahidi, F. 2010. Content of insoluble bound phenolics in millets and their contribution to antioxidant capacity. Journal of Agriculture and Food Chemistry, 58, 6706- 6714.

Chandrasekara, A., and Shahidi, F. 2011b. Antioxidant phenolics of millet control 
lipid peroxidation in human low density lipoproteins cholesterol and food systems. Journal of American Oil Chemists Society, 11, 1905-1918.

Chandrasekara, A., and Shahidi, F. 2011c. Antiproliferative potential and DNA scission inhibitory activity of phenolics from whole millet grains. Journal of Functional Foods, 3,159-170.

Chaudhary, M.G., 2013. Development of Probiotic Ice Cream Supplemented with Finger Millet (Finger millet). M.Tech. Thesis. Anand Agricultural University, Anand, Gujarat, India.

Chethan, S., and Malleshi, N.G. 2007. Finger millet polyphenols: Optimization of extraction and the effect of $\mathrm{pH}$ on their stability. Fd. Chem, 105, 862-870.

Chilakawar, P.M., and Pawar, V.S., 2015. Preparation of health food from finger millet malt. Bioinfolet, 12 (2 A), 403404.

Dayakar Rao, B., Bhaskarachary, K., Rajendra Prasad, M.P., Bala Krishna, D., Dhanasri, K., and Nageswara Rao, T.G. 2016. Nutritional and Health Benefits of Millets. ICAR- Indian Institute of Millets Research, Rajendranagar, Hyderabad, pp 86.ISBN- 81-89335-553.

Desai, D.A., Kulkarni, S.S., Sahoo, A.K., Ranveer, R.C., Dandge, P.B. 2010. Effect of Supplementation of Malted Finger millet Flour on the Nutritional and Sensorial Quality Characteristics of Cake Advance. J. Fd. Sci. Technol, 2 (1), 6771.

Glew, R.S., Chuang, L.T., Roberts, J.L., and Glew, R.H. 2008. Amino acid, fatty acid and mineral content of black finger millet (Eleusinecoracana) cultivated on the Jos plateau of Nigeria. Food, 2(2), 115-118.

Gopalan, C., Rama Sastri, B.V., and Balasubramanian, S. C. 2009. Nutritive value of Indian foods. Hyderabad, India: National Institute of Nutrition, Indian Council of Medical Research.

Isingoma, B.E., Samuel, M., Edward, K., and Maina, G. 2015. Improving the nutritional value of traditional finger millet porridges for children aged 7-24 months in Bujenje County of Western Uganda. African J. of Fd. Sci, 9 (8), 426-436.

Lye, H.S., Kuan, C.Y., Ewe, J.A., Fung, W.Y., and Liong, M.T. 2009. The improvement of hypertension by probiotics: effects on cholesterol, diabetes, renin, and phytoestrogens. Int J MolSci, 10 (9), 3755-3775.

Malleshi, 2002a. Malting of finger millet (Eleusinecoracana) and specialty foods based on the millet malt. In: Sovenier, XV Indian convention of Food Scientists and Technologist, AFST (I), Maysore, pp.17-23

Manay, N.S., and Shadaksharaswamy, M. 2001. Cereals. In Foods, Facts and Principles. 2nd Ed. New Age Int. (Pvt). Ltd. Pub., New Delhi, pp-11.

Manisseri, C., and Gudipati, M. 2012. Prebiotic Activity of Purified Xylobiose Obtained from Ragi (Eleusinecoracana,) Bran. Indian Journal of Microbiology, 52 (2), 251-257.

Martensson, O., Oste, R., and Holst, O. 2002. The effect of yoghurt culture on the survival of probiotic bacteria in oat-based, non-dairy products. Food Res. Int, 35, 775-784.

Mathanghi, S.K., and Sudha, K. 2012. Functional and phytochemical properties of finger millet (Eleusinecoracana L.) for health. International Journal of Pharmaceutical, Chemical and biological sciences, 2 (4), 431-438.

Modha, H., and Pal, D. 2011. Optimization of Rabadi-like fermented milk beverage using pearl millet. J Food SciTechnol, 48, 190-196.

Mugocha, P.T., Taylor, J.R.N., and Bester, B.H. 2000. Fermentation of a composite finger millet-dairy beverage. World Journal of Microbiology and Biotechnology, 16, 341-344.

Mutoni, H., 2011. Formulation of pearl milletmilk based set yoghurt. M.Tech. Thesis submitted to National Dairy Research Institute, Deemed University, Karnal.

Pardhi, P.S., Desale, R.J., Mule, P.R., Ghule, 
B.K., Tambe, D.R., and Gavhane, M.S. 2014. Studies on finger millet lassi. Asian J. Dairy \& Food Res, 33 (4), 255-258.

Patel, I.J., Dharaiya, C.N., and Pinto, S.V. 2015. Development of technology for manufacture of finger millet ice cream. $J$. Food Sci. Technol, 52 (7), 4015-4028.

Pintu, R.K., 2006. Development of a Rabadilike fermented beverage from sorghum and milk solids. M.Tech. (D.T.) Thesis. National Dairy Research Institute (Deemed University), Karnal.

Rachie, K.O., and Peters, L.V. 2002. Pseudocereals and Less Common Cereals: Grain Properties and Utilization Potential, Belton, P., and Taylor. J., Eds., SpringerVerlag: Berlin.

Rajasekaran, N.S., Nithya, M., Rose, C., and Chandra, T.S. 2004. The effect of finger millet feeding on the early responses during the process of wound healing in diabetic rats. BiochimBiophys. Acta, 89(3), 190-201.

Shivakumar, A., Arunkumar, H., and Venkatesh, M.V. 2014. Process optimization for the production of paneer (soft cheese) kheer blended with Foxtail millet and Finger millet flour. Journal of Research in Agriculture and Animal Science. pp. 06-09.

Shobana, S., Krishnaswamy, K., Sudha, V., Malleshi, N.G., Anjana, R.M., Palaniappan, L., and Mohan, V. 2013. Finger millet (Elusinecorcana L): a review of its nutritional properties, processing and plausible health benefits. Adv.FoodNutr.Res, 69, 01- 39.

Steel, R.G.D., and Torrie, J.H. 1980. Principles and procedures of statistics- A Biometrical approach, 2nd Edn, McGrawHill, New York. pp: 137-167.

Stone, H., and Sidel, J.L. 1993. The role of sensory evaluation in the food industry. Food Quality and Preference, Academic Press, San Diego, pp.65-73.

Tarakci, Z., Dogan, I.S., and Koca, A.F. 2004. A traditional fermented Turkish soup, tarhana, formulated with corn flour and whey. International Journal of Food Science and Technology, 39, 455-458.

Taylor, J.R.N., and Emmambux, M.N. 2008 Gluten-free foods and beverages from millets. In: Gallagher E, editor. Glutenfree cereal products and beverages. Burlington, MA: Elsevier, pp: 1-27.

Taylor, J.R.N., Schober, T.J., and Bean, S.R. 2006. Novel food and non-food uses for sorghum and millets. Journal of Cereal Science, 44 (30), 252-271.

Thompson, L.U., 1993. Potential health benefits and problems associated with antinutrients. Fd. Res. Int, 26, 131-149.

Trivedi, J.B., 2014. Biochemical characteristics and health benefits of fermented beverage prepared from blend of oat and cow milk. M. Sc. Thesis. Submitted to Gujarat Agricultural University, Anand.

\section{How to cite this article:}

Aijaz M. Shaikh, V. Sreeja and Rachana R. Desai. 2017. Effect of Malted and Unmalted Finger Millet Flour and Its Rates of Incorporation on Quality Attributes of Finger Millet Enriched Probiotic Fermented Milk Product. Int.J.Curr.Microbiol.App.Sci. 6(9): 2258-2266. doi: https://doi.org/10.20546/ijcmas.2017.609.277 